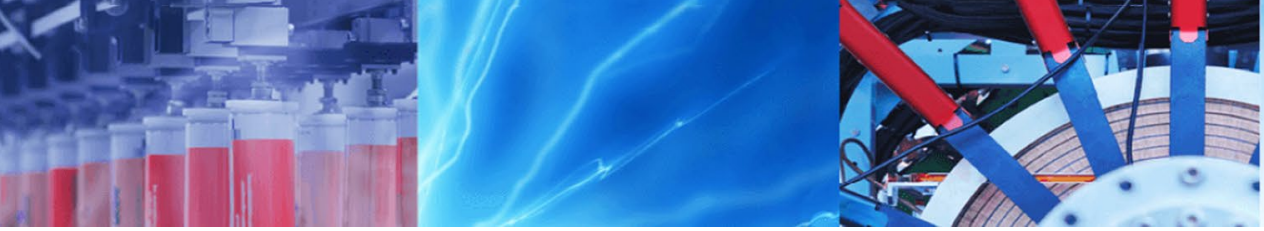

Research Article

\title{
Phase and dimensional stability of volcanic ash-based phosphate inorganic polymers at elevated temperatures
}

\author{
Jean Noël Yankwa Djobo ${ }^{1,2} \cdot$ Antoine Elimbi $^{3} \cdot$ Dietmar Stephan $^{2}$
}

Received: 14 October 2019 / Accepted: 26 March 2020 / Published online: 6 April 2020

(C) The Author(s) $2020 \quad$ OPEN

\begin{abstract}
Phosphate geopolymers are part of chemically bonded phosphate cements obtained from an aluminosilicate and phosphate solution. Their structure consisting of phosphate bonds makes them suitable for use as refractory material. This study deals with the influence of phosphoric acid concentration $(6,8$ and $10 \mathrm{~mol} / \mathrm{L})$ on the stability of volcanic ash-based phosphate geopolymers exposed to 100,600 and $1000{ }^{\circ} \mathrm{C}$. The results reveal that the onset of crystallization is about $600^{\circ} \mathrm{C}$ with the formation of aluminum phosphate (V) and tridymite, then crystallization of iron (III) phosphate (V) and hematite at $1000^{\circ} \mathrm{C}$. The degree of crystallization of these phases increases with phosphoric acid concentration. The geopolymers obtained with $8 \mathrm{~mol} / \mathrm{L}$ of phosphoric acid showed the best thermal stability at $1000^{\circ} \mathrm{C}$ in terms of compressive strength change. The maximum thermal linear shrinkage recorded was $3 \%$. The major phases of all geopolymers remain stable up to $1000^{\circ} \mathrm{C}$, after which the melting of phases happens.
\end{abstract}

Keywords Volcanic ash · Phosphate geopolymers · Thermal stability

\section{Introduction}

Geopolymers are known as 3D network inorganic polymer obtained by chemical reaction of a solid precursor (aluminosilicate) and an alkaline or acidic medium [1]. Sometimes the alkaline part in powder form is directly mixed with the aluminosilicate and water used as liquid phase to make the binder. In that case it is called one-part geopolymer [2]. The geopolymer gained popularity because of the potential low $\mathrm{CO}_{2}$ emission and energy efficiency during its manufacturing compared to conventional cement $[3,4]$. Moreover, the superior thermal stability of geopolymer compared to Portland cement has also increased the interest in that material for high-temperature applications [5]. However, this characteristic is closely related to the type of aluminosilicate used as well as the synthesis conditions [6-8]. For example, an addition of calcium sources to Metakaolin (MK) improves the thermal resistance of geopolymers in terms of compressive strength compared to solely MK-based geopolymers when exposed at $1000{ }^{\circ} \mathrm{C}$ [9]. It was reported a loss of $40 \%$ of initial strength after a cycle of heating-cooling of geopolymer from volcanic ash at $1000^{\circ} \mathrm{C}$ [10]. When prepared in an alkaline medium, the phases of volcanic ash-based geopolymers are not stable beyond $1000^{\circ} \mathrm{C}$ as they start melting contrary to MK-based ones. It was also shown that volcanic ash based-geopolymers obtained with potassium silicate as alkaline solution develops superior stability at elevated temperatures with thermal shrinkage less than $3 \%$ compared to the ones with sodium silicate [11]. In general, when exposed to elevated temperatures the physical properties of geopolymers obtained in alkaline solution are significantly deteriorated in the range of $750-900$ oC $[12,13]$. The latter constitutes the highest temperature range of application of geopolymer obtained in alkaline medium in the field of

$\triangle$ Jean Noël Yankwa Djobo, noeldjobo@gmail.com; noel.djobo@campus.tu-berlin.de | ${ }^{1}$ Local Materials Promotion Authority/MIPROMALO/MINRESI, Nkolbikok, 2396 Yaoundé, Cameroon. ${ }^{2}$ Building Materials and Construction Chemistry, Technische Universität Berlin, Gustav-Meyer-Allee 25, 13355 Berlin, Germany. ${ }^{3}$ Department of Inorganic Chemistry, Faculty of Science, University of Yaoundé 1,812 Yaoundé, Cameroon. 
heat resistance materials. This is due to cations present in the alkaline solution which lower the temperature of glass transition, hence induce sintering with the decrease of the mechanical strength along with severe thermal shrinkage $[8,11]$. Up to now, few studies deal with the phase stability or physical properties of geopolymers obtained in an acidic medium after exposure at elevated temperatures.

The phases of MK-based geopolymers obtained with phosphoric acid were reported to be thermally stable, with linear shrinkage of $5.3 \%$ after exposure at $1450^{\circ} \mathrm{C}$ [14]. Also, phosphoric acid activation of synthetic $\mathrm{Al}_{2} \mathrm{O}_{3}-2 \mathrm{SiO}_{2}$ powders showed extremely high thermal stability of phases with no sign of melting up to $1550{ }^{\circ} \mathrm{C}$ [15]. Recent work reported that the structural evolution of phases with temperature and their stability depend on the phosphate content of the matrix [16]. However, MK-based phosphate geopolymers have low thermal stability in terms of compressive strength evolution. Bewa et al. reported a decrease of more than $75 \%$ of the compressive strength development only after exposure at $200^{\circ} \mathrm{C}$ [17]. While Celerier et al. [18] showed the complete destruction and/or extensive cracks apparition with a significant decrease of the compressive strength of MK-based phosphate geopolymer after heating to $1000^{\circ} \mathrm{C}$. These behaviours at elevated temperatures depend on the $\mathrm{Al} / \mathrm{P}$ ratio of the matrix, the reactivity of the MK used and its wettability. Moreover, the high-water content of the MKbased phosphate geopolymer was also responsible of the destruction of the binding phase because of the dehydroxylation that happens after heating. Since MK particles have a high specific surface area, thus high-water demand and high liquid to solid mass ratio are required for reaching good workability.

The investigation of geopolymers from volcanic ash and phosphoric acid has never been reported yet. Since the improved thermal stability of phases of MK-phosphate geopolymer was due to the high stability of the phosphate bond, the low thermal stability of phases of volcanic ash-based geopolymer in alkaline solution could also be improved when synthesized in acidic medium. Moreover, volcanic ash has a lower specific surface area compared to MK and generally low liquid to solid mass ratio is required for achieving good workability [19]. This work aims to investigate the influence of phosphoric acid concentration on the thermal stability of volcanic ash-based phosphate geopolymers for hightemperature applications. These include the study of the transformation and transition of phases, the thermal shrinkage as well as porosity and compressive strength of geopolymers exposed to high temperatures. The thermal transformation and transition of phases were investigated by X-ray diffractometry (XRD), Fourier transformed infrared spectroscopy (FTIR), Thermogravimetry analysis coupled with Differential Scanning Calorimetry (TGA-DSC) and Dilatometry analysis. The porosity was determined using mercury intrusion porosimeter (MIP) and the microstructure by using scanning electron microscope with energy dispersive $\mathrm{X}$-ray spectroscopy.

\section{Materials and methods}

\subsection{Materials}

Volcanic ash (VA) was collected along "the Line of Cameroon" and ground in a ball mill to get a powder with particle size $<200 \mu \mathrm{m}$. The chemical analysis carried out by X-ray fluorescence is reported in Table 1 . The particle size distribution carried out using a laser particle size analyzer (MASTERSIZER S, Malvern, UK) is depicted in Fig. 1. It shows a trimodal distribution with characteristic diameters as follows: $d_{10}=0.26 \mu \mathrm{m} \mathrm{d}_{50}=3.7 \mu \mathrm{m}$ and $\mathrm{d}_{90}=57 \mu \mathrm{m}$. Orthophosphoric acid $\left(\mathrm{H}_{3} \mathrm{PO}_{4}, 85 \mathrm{wt} \%\right)$ was used to prepare the hardeners. The latter were obtained by diluting the as received orthophosphoric acid with water to get concentrations of phosphoric acid solution 6,8 and $10 \mathrm{~mol} / \mathrm{L}$.

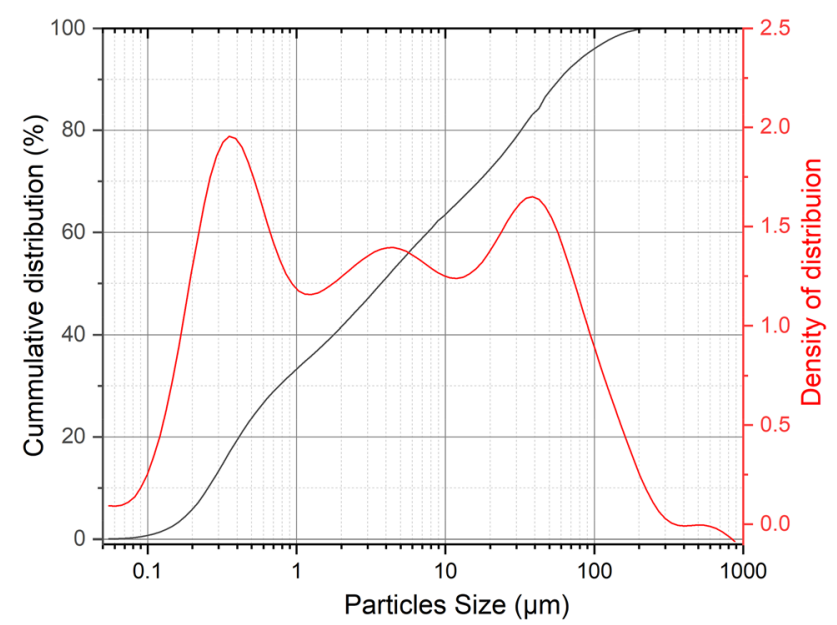

Fig. 1 Particles size distribution of milled volcanic ash
Table 1 Chemical composition of volcanic ash

SN Applied Sciences

\begin{tabular}{lllllllllllll}
\hline Oxides & $\mathrm{SiO}_{2}$ & $\mathrm{Al}_{2} \mathrm{O}_{3}$ & $\mathrm{Fe}_{2} \mathrm{O}_{3}$ & $\mathrm{CaO}$ & $\mathrm{MgO}$ & $\mathrm{Na}_{2} \mathrm{O}$ & $\mathrm{TiO}_{2}$ & $\mathrm{~K}_{2} \mathrm{O}$ & $\mathrm{MnO}$ & $\mathrm{P}_{2} \mathrm{O}_{5}$ & LOI & Total \\
\hline $\mathrm{wt} \%$ & 40.41 & 15.90 & 13.46 & 8.87 & 8.45 & 1.75 & 3.08 & 0.91 & 0.21 & 0.88 & 4.25 & 98.17 \\
\hline
\end{tabular}




\subsection{Experimental methods}

The geopolymer pastes were prepared by mixing in an automatic Hobart mixer for 3 min volcanic ash and phosphoric acid according to liquid to solid mass ratios of $0.32,0.36$ and 0.4 respectively. These different ratios were chosen according to the texture of each paste which allows easy pouring in the mold before losing any workability. The pastes obtained were poured in $40 \mathrm{~mm}$ cubic moulds, vibrated for $3 \mathrm{~min}$ and covered with a plastic foil to avoid cracks or pores due to rapid water evaporation. The specimens were kept at $27 \pm 3{ }^{\circ} \mathrm{C}$ and $62 \%$ Relative humidity for $24 \mathrm{~h}$ before demolding, then stored in the same curing condition for $28 \mathrm{~d}$. Afterward, the geopolymer specimens were heated to a temperature of 100, 600 and $1000^{\circ} \mathrm{C}$ at a heating rate of $5^{\circ} \mathrm{C} / \mathrm{min}$ in a programmable electrical furnace and kept at this temperature for $4 \mathrm{~h}$. The analysis of the mineralogical composition of the geopolymers before and after exposure to elevated temperatures was carried out using X-ray diffractometry (Bruker X-ray diffractometer (D8 Discovery, US)). The device operates with Cu Ka1 radiation $(\lambda=1.54 \AA)$, at $35 \mathrm{kV}, 45 \mathrm{~mA}$. The XRD patterns were recorded in the range of $15-70^{\circ} 2 \theta$. The changes in the chemical bonds of unheated and heated geopolymers were investigated by FTIR spectroscopy (Nicolet 5700 spectrometer). The analysis was carried out on $\mathrm{KBr}$ pellets. For each sample, 32 scans with a resolution of $4 \mathrm{~cm}^{-1}$ were recorded in the frequency range $4000-400 \mathrm{~cm}^{-1}$. The porosity and pore size distribution of unheated geopolymers were investigated by mercury intrusion porosimeter (Auto pore IV 9500 Micromeritics) It operates with the set-time equilibrium of $10 \mathrm{~s}$ and pressure ranges of $345 \mathrm{kPa}$ and $228 \mathrm{MPa}$ that allows to measure pore size range between 0.005 and $360 \mu \mathrm{m}$. The compressive strength of geopolymers before and after exposure to elevated temperatures was measured thanks to an automatic compressive test machine (Impact Test Equipment Limited) with a maximum load of $250 \mathrm{KN}$. The microstructure was carried out on unheated geopolymer using Zeiss Gemini SEM 500 NanoVP microscope (Oberkochen, Germany) coupled with an Energy-Dispersive X-ray spectroscopy (EDX) that operate at low-Vacuum mode with $15 \mathrm{kV}$ acceleration voltage.

Thermal transformation and transition phases were monitored using Thermogravimetry analysis coupled with Differential Scanning Calorimetry (Linseis, Model STA PT1000). The equipment operated in the temperature ranges $20-1000{ }^{\circ} \mathrm{C}$ with a heating rate of $20^{\circ} \mathrm{C} / \mathrm{min}$ at an ambient atmosphere. An optical dilatometer (ESS MISURA HSM ODHT Model 1600/80) was used to assess changes of length of specimens shaped $5 \times 5 \times 15 \mathrm{~mm}^{3}$.

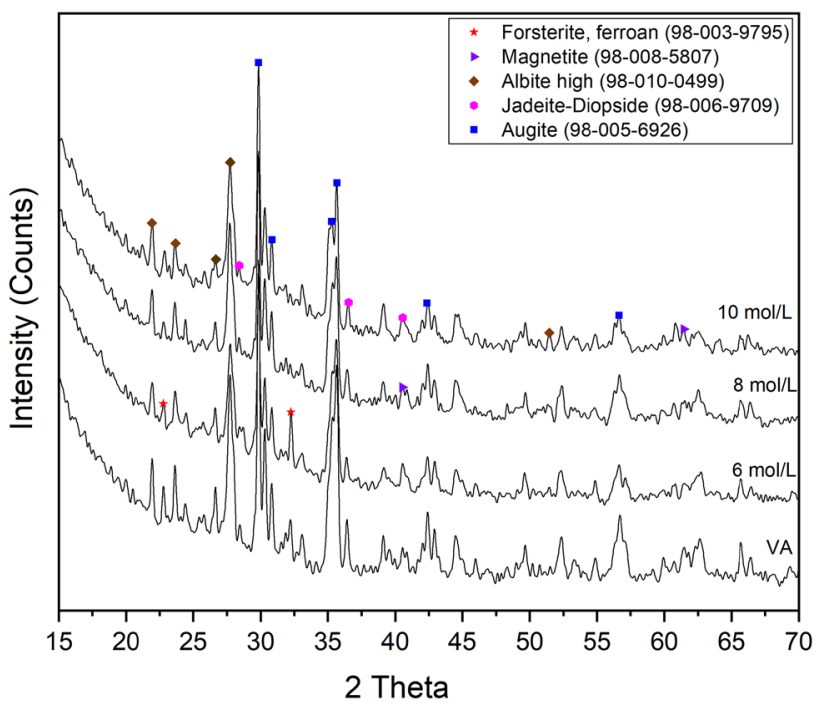

Fig. 2 X-ray patterns of volcanic ash and resulting geopolymers at $27^{\circ} \mathrm{C}$

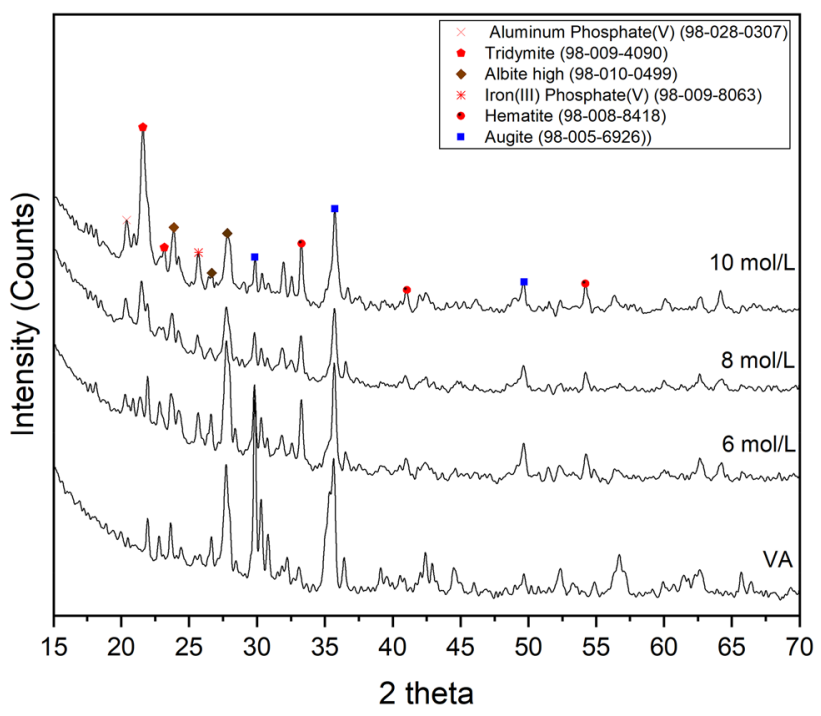

Fig. 3 X-ray patterns of geopolymer after heating at $1000^{\circ} \mathrm{C}$

\section{Results and discussion}

\subsection{Influence of phosphoric acid concentration on mineralogy at 27 and $1000^{\circ} \mathrm{C}$}

The phase compositions of raw volcanic ash and geopolymers before and after exposure to $1000{ }^{\circ} \mathrm{C}$ are depicted in Figs. 2 and 3 respectively. The main minerals identified in volcanic ash using X'Pert High Score Plus software are as follows: augite (PDF\# 98-005-6926); albite high (PDF\# 98-010-0499); jadeite-diopside (PDF\# 98-006-9709); 
forsterite, ferroan (PDF\# 98-003-9795) and magnetite (PDF\# 98-008-5807). In the unheated geopolymers, no new crystalline phases were identified (Fig. 2), but a significant decrease of peaks intensity of major minerals is visible. This behaviour is like what happens with volcanic ash-based geopolymers obtained in alkaline solution [20, 21]. The intensities of the peaks of augite (Al0.1 Ca0.83Fe 0 .34Mg0.77Na0.0206Si1.92Ti0.02) at $29.80^{\circ}(2.99 \AA), 35.53^{\circ}$ $(2.52 \AA)$ and $35.74^{\circ}(2.51 \AA)$ respectively decrease by 38 , 27 and $28 \%$ respectively after reaction of volcanic ash with $6 \mathrm{~mol} / \mathrm{L}$ acid solution. Also, intensities of the main peaks of albite $\left(\mathrm{NaAlSi}_{3} \mathrm{O}_{8}\right)$ at $2 \theta=27.73^{\circ}(3.21 \AA), 23.57^{\circ}$ $\left(3.77 \AA\right.$ ) and $21.87^{\circ}(4.05 \AA$ ) respectively are reduced by 26,22 and $17 \%$ respectively. These data show that augite is more dissolved than albite. This is likely due to the preferential dissolution of augite (Pyroxene group) in low $\mathrm{pH}$ (below 3-4) in comparison with albite (Feldspar group) [22, 23]. However, the extent of dissolution of those minerals is not proportional to the acid concentration, though it remains low in volcanic ash. A tentative explanation of this behaviour might be the rapid dissolution of amorphous phase and fast setting as observed during mixing, which would have delayed the further dissolution of unreacted particles with time. Nevertheless, a deep investigation to understand the dissolution behaviour of volcanic ash in an acidic medium is requires and this will be carried out in our upcoming studies.

The X-ray patterns of heated geopolymers at $1000^{\circ} \mathrm{C}$ (Fig. 3) show several changes in the phase compositions compared to unheated ones. The main diffraction peaks of minerals like Jadeite-Diopside (PDF\# 98-006-9709); Forsterite, ferroan (PDF\# 98-003-9795) and Magnetite (PDF\# 98-008-5807) are no longer identifiable, which means that they were transformed into other phases. It can also be seen the significant decrease of intensities of peaks at $2 \theta=29.80^{\circ}(2.99 \AA)$ and $27.74^{\circ}(3.21 \AA)$ corresponding to the main peak of augite and albite respectively with acid concentration. This happens along with the change in the profile of the broad peak at $2 \theta=35.74(2.51 \AA)$ on the $X$-ray pattern of volcanic ash which becomes narrow. The extent of the decrease of the main peak intensity of these major minerals shows that in addition to acid concentration, the stability of augite is more sensitive to temperature than albite. The new crystalline phases are aluminum phosphate (V) (PDF\# 98-028-0307), tridymite (PDF\# 98-009-4090), hematite (PDF\# 98-008-8418) and iron (III) phosphate (V) (PDF\# 98-009-8063). Their main peaks are as follows: $2 \theta=20.46^{\circ}(4.33 \AA), 21.52^{\circ}(4.12 \AA)$ and $23.15^{\circ}$ $(3.84 \AA)$ for aluminium phosphate $(V) ; 2 \theta=20.32^{\circ}(4.36$ $\AA), 21.62^{\circ}(4.10 \AA)$ and $23.08^{\circ}$ (3.85 $\AA$ ) for tridymite); $2 \theta=25.68^{\circ}(3.46 \AA), 37.63^{\circ}\left(2.38 \AA\right.$ ) and $20.33^{\circ}(4.36 \AA)$ for iron(III) phosphate(V); $2 \theta=33.25^{\circ}(2.69 \AA), 35.72^{\circ}(2.51 \AA)$ and $54.23^{\circ}(1.70 \AA)$ for hematite. Iron phosphate minerals have a similar structure like the $\mathrm{SiO}_{2}$-based minerals [24]. It can be noticed an increase of these main peak intensities with the increase of phosphoric acid concentration. The formation of aluminum phosphate $(\mathrm{V})$ and silica-based minerals such as tridymite are common in phosphate geopolymers treated at $1000^{\circ} \mathrm{C}[15,17,25-27]$. The formation of these two minerals is due to the crystallization of amorphous $\mathrm{AlPO}_{4}-\mathrm{SiO}_{2}$ solid solution constituting the binding phase of the phosphoric acid-based geopolymer [27]. Thus, the increase of the amount of these minerals demonstrates the extent of dissolution of reactive phases that happens with the increase of phosphoric acid concentration. Moreover, the formation of hematite and iron phosphate is new in high-temperature heating of phosphate geopolymers. Their presence is the proof that in addition to $\mathrm{AlPO}_{4}-\mathrm{SiO}_{2}$ solid solution as binder in phosphate geopolymer there is also $\mathrm{FePO}_{4}$ in the case of ferroaluminosilicate materials like volcanic ash. Moreover, similarly to aluminum phosphate and tridymite, the presence of hematite and iron phosphate comes from the partial breakdown of the Fe-O-P bonds of the amorphous phase of the geopolymer binder.

Structural bond changes in geopolymer with varying phosphoric acid concentration before and after exposure to elevated temperatures are highlighted in Figs. 4 and 5 respectively. The vibration band appearing at 1650 and $3420 \mathrm{~cm}^{-1}$ in all IR spectra are respectively characteristic of bending and stretching vibrations of $\mathrm{H}-\mathrm{O}-\mathrm{H}$ and $\mathrm{H}-\mathrm{O}$ bonds of water molecules. In Fig. 4, the band on VA at $1020 \mathrm{~cm}^{-1}$ is characteristic of stretching vibrations of $\mathrm{Si}-\mathrm{O}$ bonds of silicate chain. With $6 \mathrm{~mol} / \mathrm{L}$ of phosphoric acid used as a hardener, that band has shifted by about $52 \mathrm{~cm}^{-1}$ to a higher value after geopolymerization.

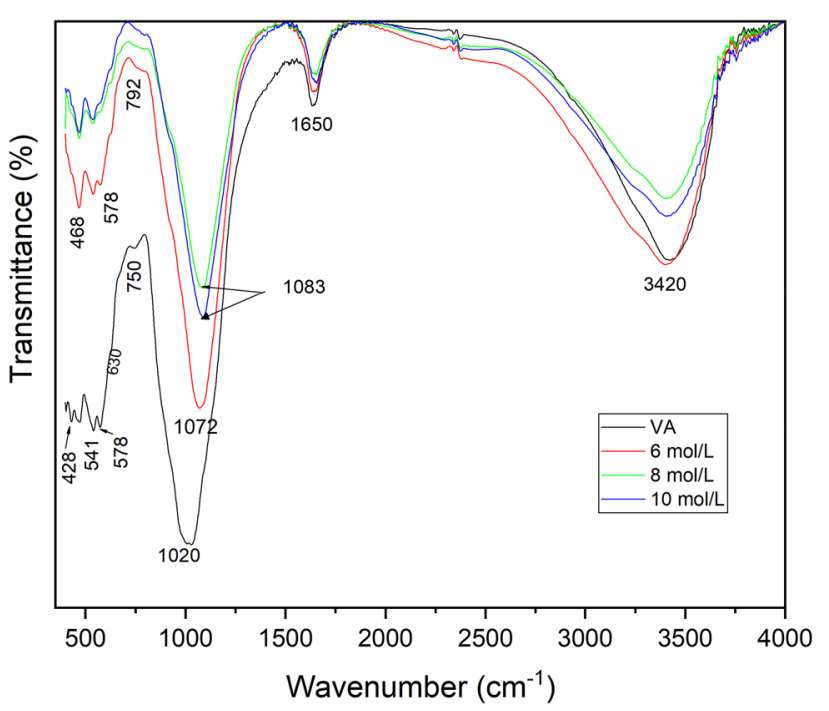

Fig. 4 IR spectra of volcanic ash and resulting geopolymers at $27^{\circ} \mathrm{C}$ 


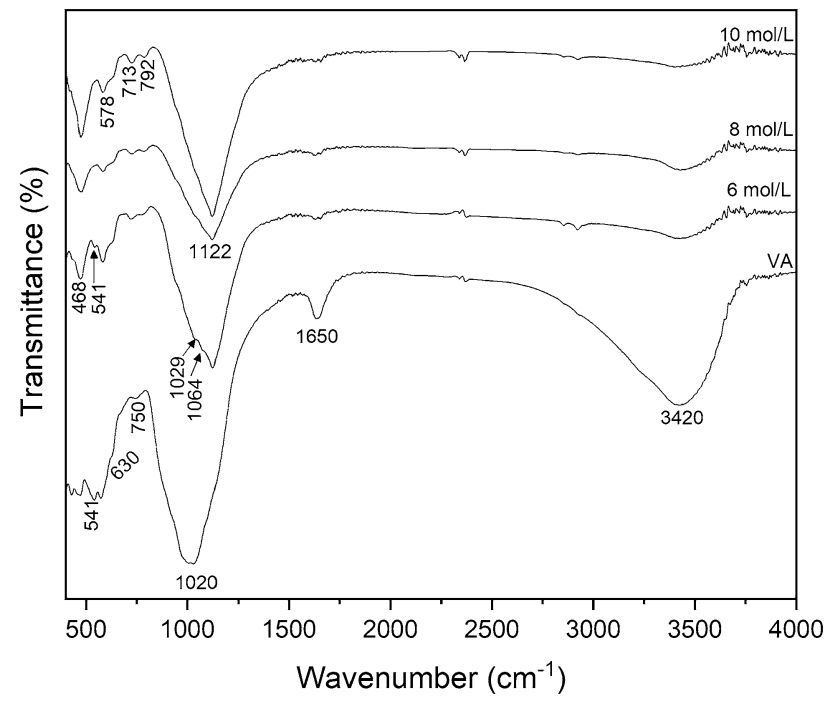

Fig. 5 IR spectra of geopolymer after heating at $1000^{\circ} \mathrm{C}$

It further shifted by $11 \mathrm{~cm}^{-1}$ when the acid concentration rises respectively to 8 and $10 \mathrm{~mol} / \mathrm{L}$. Such change is also noticeable on the band at $750 \mathrm{~cm}^{-1}$ of volcanic ash, which is characteristic of stretching vibration of $\mathrm{Si}-\mathrm{O}$ bonds of the silicate network, that shifted to $792 \mathrm{~cm}^{-1}$ on geopolymer. This observation indicates that there is a formation of new bonds as a result of reaction occurring $[21,28]$. Such a phenomenon can be attributed to the formation of the polymeric structure of geopolymer binder which structural unit includes connection among tetrahedra $\left[\mathrm{AlO}_{4}\right]^{5-},\left[\mathrm{FeO}_{4}\right]^{5-}$ and $\left[\mathrm{PO}_{4}\right]^{5-}$. The changes observed in that main vibration band also ascertain that increasing the concentration of phosphoric acid improves the extent of the dissolution of reactive phases as stated by XRD patterns. The bands appearing at 630 , 578 and $541 \mathrm{~cm}^{-1}$ are respectively related to the various vibrating modes of the $\mathrm{Si}-\mathrm{O}$ bonds in the silicate chains of volcanic ash [29].

Figure 5. shows the IR spectra of geopolymer with varying acid concentration after heating at $1000^{\circ} \mathrm{C}$. After heating geopolymer, there is a significant decrease in the intensity of bands at 3420 and $1650 \mathrm{~cm}^{-1}$ which are characteristic of vibration modes of water molecules. Compared to the IR spectra of geopolymer cured at $27^{\circ} \mathrm{C}$ (Fig. 4.) it can also be observed a shift of the wavenumber of the main band characteristic of $\mathrm{Si}-\mathrm{O}$ vibration $\left(1072-1083 \mathrm{~cm}^{-1}\right)$ to a higher value $\left(1112 \mathrm{~cm}^{-1}\right)$ and the apparition of new bands at 1029 and $1064 \mathrm{~cm}^{-1}$ respectively. Other changes are the disappearance of the vibration band at $541 \mathrm{~cm}^{-1}$ and the appearance of the band at $713 \mathrm{~cm}^{-1}$ after heating. Similar changes were observed in previous work $[16,17]$. In this study, these changes are

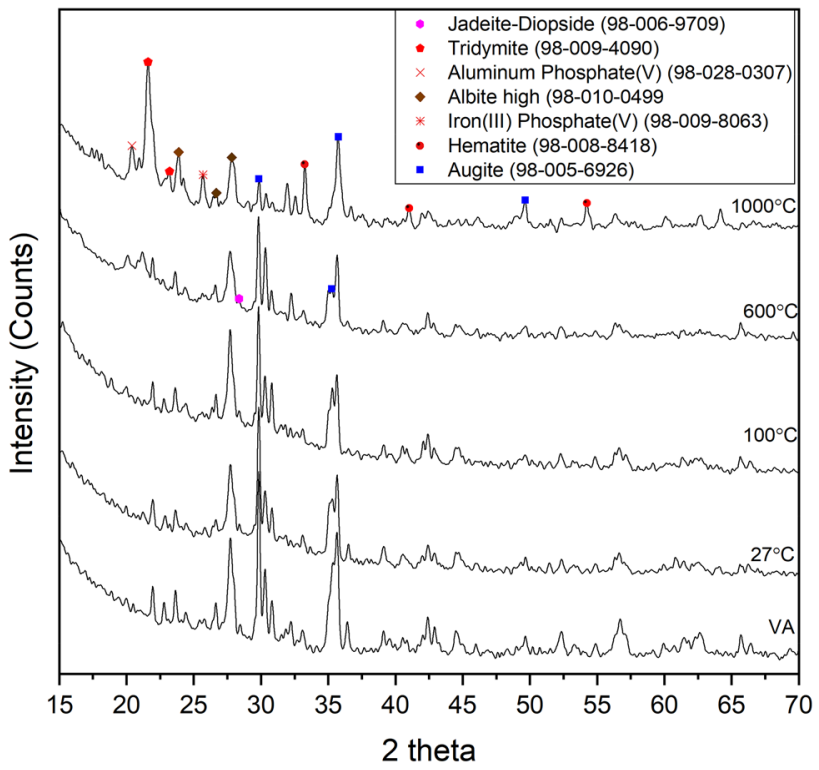

Fig. 6 X-ray patterns of geopolymer obtained with $10 \mathrm{~mol} / \mathrm{L}$ acid concentration after heating at various

attributed to the crystallization of tridymite and phosphate minerals as shown in XRD patterns of geopolymer after heating at $1000^{\circ} \mathrm{C}$.

\subsection{Influence of heating temperature on the mineralogy of phosphate geopolymer obtained with $10 \mathrm{~mol} / \mathrm{L}$ acid concentration}

Figure 6 shows the X-ray patterns of volcanic ash-based geopolymers obtained with $10 \mathrm{~mol} / \mathrm{L}$ of phosphoric acid after exposure to various temperatures. As it can be seen, the crystalline phases initially present in unheated geopolymers remain stable up to $600{ }^{\circ} \mathrm{C}$, where the onset of crystallisation is observed. The latter phenomenon is however characterized by the formation of new minerals, aluminum phosphate (V) (PDF\# 98-028-0307) and tridymite (PDF\# 98-009-4090). Although the initial minerals remain up to $600^{\circ} \mathrm{C}$, their peak intensities somewhat diminish with increasing temperature. This is more prominent at $1000^{\circ} \mathrm{C}$ where other new minerals (hematite and iron (III) phosphate (V)) are formed along with the disappearance of some of the initial ones (jadeitediopside; forsterite, ferroan and magnetite). There is also a significant increase of the peak intensities of aluminum phosphate $(\mathrm{V})$ and tridymite at $1000^{\circ} \mathrm{C}$. It arises from these results that, the stability of minerals of the studied system is temperature sensitive and the onset of crystallization is at around $600{ }^{\circ} \mathrm{C}$. 


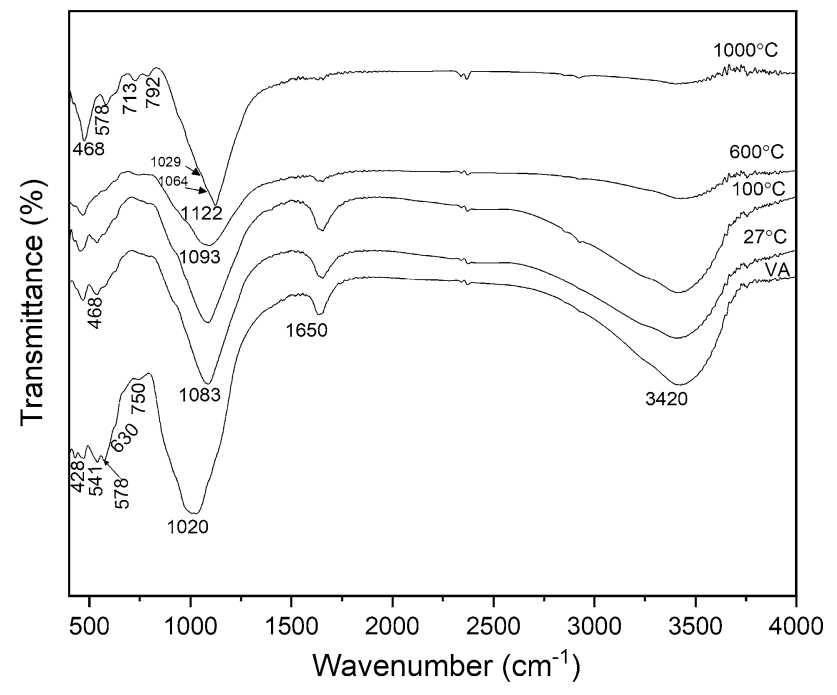

Fig. 7 IR spectra of geopolymer obtained with $10 \mathrm{~mol} / \mathrm{L}$ acid concentration after heating at various temperatures

\subsection{Physical characteristics and microstructure}

The IR spectra of geopolymers obtained with $10 \mathrm{~mol} / \mathrm{L}$ of phosphoric acid and heated at various temperatures are shown in (Fig. 7). The effect of heating is highlighted by the main changes between 600 and $1000{ }^{\circ} \mathrm{C}$. The latter include the shift of the main vibration band from 1093 to $1122 \mathrm{~cm}^{-1}$, the disappearance of the bands at $541 \mathrm{~cm}^{-1}$ and the appearance of the bands at 713, 1029 and $1064 \mathrm{~cm}^{-1}$. These results confirm the fact that the onset of crystallisation of phosphate geopolymers is around $600^{\circ} \mathrm{C}$.

\subsubsection{Visual aspect}

After maintaining geopolymers at various temperatures, changes in colour and the formation of cracks on the surface of some specimens were observed (Fig. 8). The specimens obtained with $6 \mathrm{~mol} / \mathrm{L}$ of phosphoric acid show no sign of surface deterioration when exposed to $100^{\circ} \mathrm{C}$, whilst other specimens show some cracks. The latter
Fig. 8 The physical appearance of geopolymers before and after exposure to various temperatures

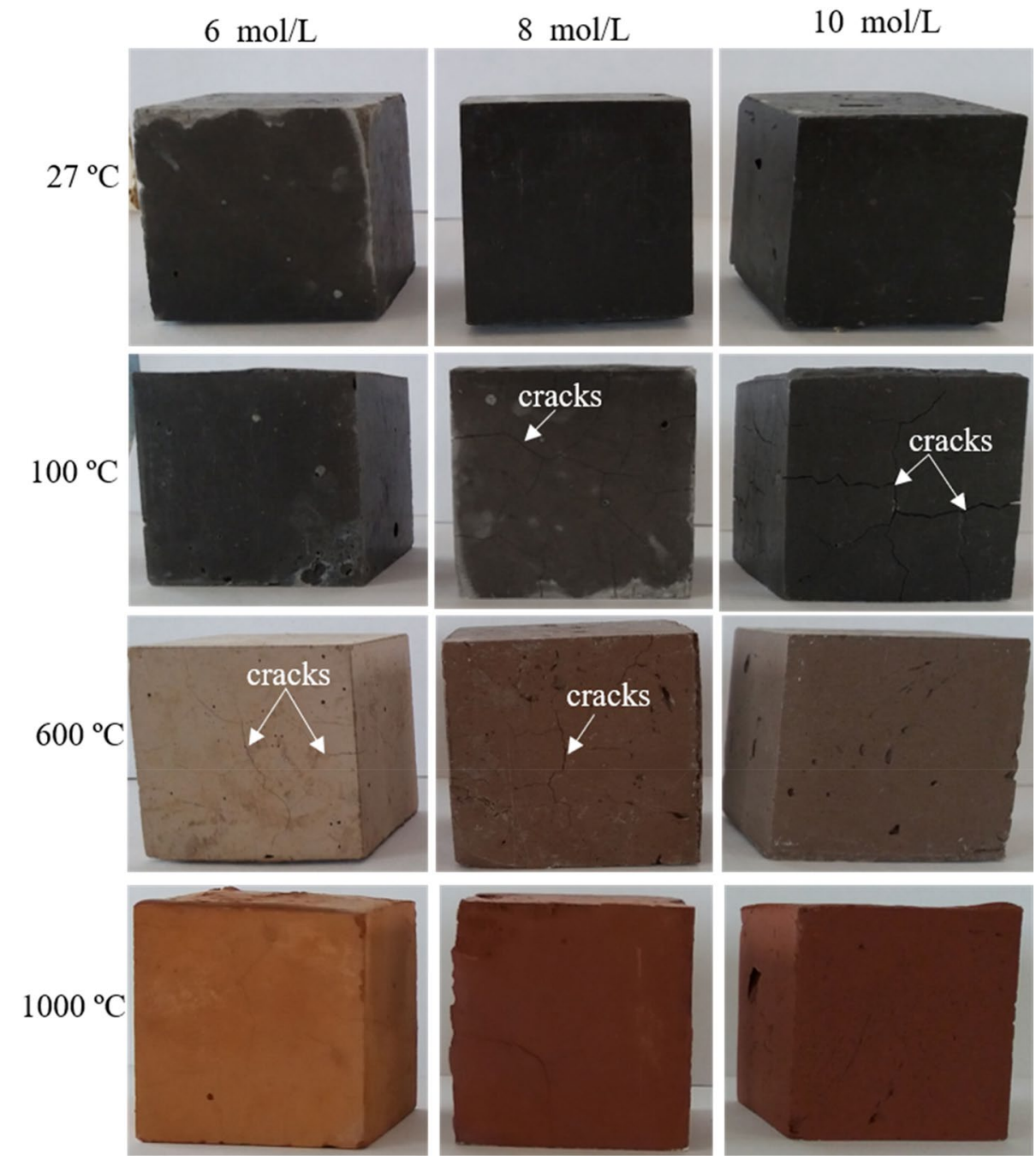


seems to be more prominent and larger on the specimen obtained with $10 \mathrm{~mol} / \mathrm{L}$ of phosphoric acid than the one obtained with the concentration of $8 \mathrm{~mol} / \mathrm{L}$. The presence of these cracks can be due to the evaporation of free water present in the pores network or to the dehydroxylation of geopolymer binder. Thus, the extent of cracks demonstrates that the geopolymer obtained with $10 \mathrm{~mol} / \mathrm{L}$ of phosphoric acid undergoes more damages at $100{ }^{\circ} \mathrm{C}$ compared to other specimens. At $600^{\circ} \mathrm{C}$, the geopolymer specimens obtained with 6 and $8 \mathrm{~mol} / \mathrm{L}$ of phosphoric acid display minor microcracks and there are changes of initial

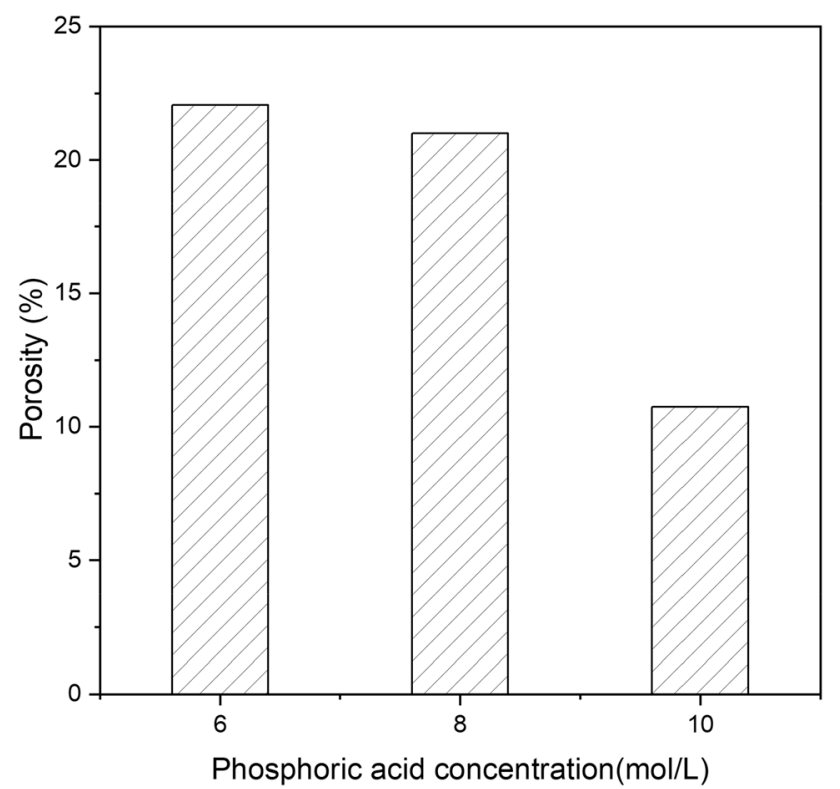

Fig. 9 Total porosity of geopolymers

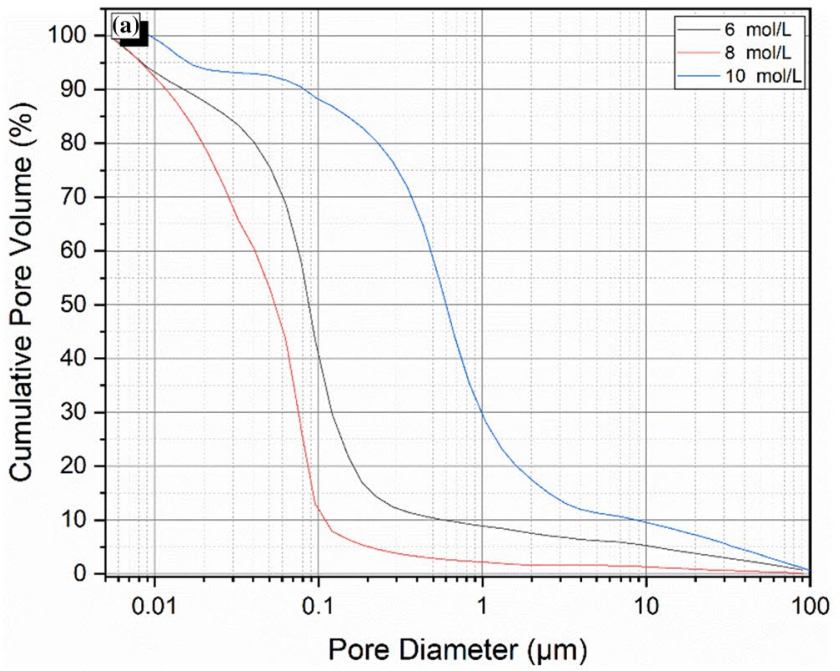

colours from black to light and dark brown. When heated to $1000^{\circ} \mathrm{C}$ all the specimens do not show any sign of external damage except the colour which is now light red and becomes dark with increasing phosphoric acid concentration. Based on a correlation between the change of colours and the mineral evolution with temperature, it can be concluded that the change of colour observed at $600^{\circ} \mathrm{C}$ results from the crystallisation of aluminium phosphate $(\mathrm{V})$ and tridymite, whereas those observed at $1000^{\circ} \mathrm{C}$ corresponds to the crystallisation of iron (III) phosphate and hematite.

\subsubsection{Porosity}

The total porosity and pore size distribution of unheated geopolymers are shown in Figs. 9 and 10 respectively. Total porosity (Fig. 9) of geopolymers obtained with 6 or $8 \mathrm{~mol} / \mathrm{L}$ of phosphoric acid are 22 and $21 \mathrm{vol} \%$ respectively. The porosity significantly decreases to $10.7 \mathrm{vol} \%$ when the acid concentration rises to $10 \mathrm{~mol} / \mathrm{L}$, which means that the latter has fewer pores compared to the formers. However, it is clearly shown in Fig. 10a that the specimen obtained with $10 \mathrm{~mol} / \mathrm{L}$ of phosphoric acid exhibits larger pore diameters than those obtained with 6 and $8 \mathrm{~mol} / \mathrm{L}$ respectively. The range of pore size (Fig. 10b)is 0.01-5 $\mu \mathrm{m}, 0.01-1 \mu \mathrm{m}$ and $0.027-5 \mu \mathrm{m}$ for specimens with 6,8 and $10 \mathrm{~mol} / \mathrm{L}$ of phosphoric acid respectively. Within these pore diameter ranges, the geopolymers obtained with 6 and $10 \mathrm{~mol} / \mathrm{L}$ of phosphoric acid have a unimodal pore diameter distribution with maxima at 0.09 and $0.55 \mu \mathrm{m}$ respectively. Whereas specimens obtained with $8 \mathrm{~mol} / \mathrm{L}$ of phosphoric acid show a bimodal distribution with maxima at 0.04 and $0.06 \mu \mathrm{m}$ respectively. The effect of pore size distribution on

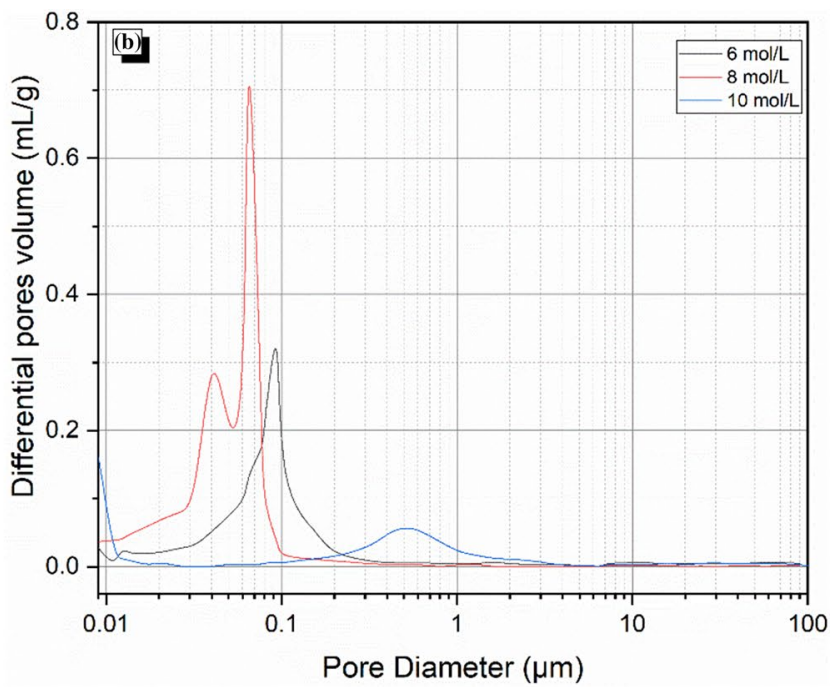

Fig. 10 Pores size distribution of geopolymers: (a) Cumulative pores volume, (b) Differential volume of intruded mercury 
the thermal stability of geopolymers will be well discussed in the next section.

\subsubsection{Compressive strength}

Figure 11 depicts the $28 \mathrm{~d}$ compressive strength evolution of geopolymer before and after heating at various temperatures for $4 \mathrm{~h}$. At room temperature, compressive strength increases with acid concentration. After heating at $100^{\circ} \mathrm{C}$, the strength of geopolymer obtained with $6 \mathrm{~mol} / \mathrm{L}$ of phosphoric acid increases by about $84 \%$ ( $49 \mathrm{MPa}$ ) while that at the other temperatures decreases. For geopolymers obtained with 8 and $10 \mathrm{~mol} / \mathrm{L}$ of phosphoric acid, the decrease of compressive strength is $14.7 \%$ ( $43 \mathrm{MPa}$ ) and $17 \%(60 \mathrm{MPa})$ respectively. This trend correlates well with the observation made on (Fig. 8) where major cracks were observed only on geopolymers obtained respectively with 8 and $10 \mathrm{~mol} / \mathrm{L}$ of phosphoric acid. These observations allow surmising that although high dissolution of reactive phase using of $6 \mathrm{~mol} / \mathrm{L}$ of phosphoric acid was observed in XRD patterns, the reaction of volcanic ash with $6 \mathrm{~mol} / \mathrm{L}$ acid concentration remains low. Thus, when exposed at $100^{\circ} \mathrm{C}$, the heat supplied rather improves the geopolymerization leading to a more condensed and stronger polymer chain. This seems to be the contrary to geopolymerization with 8 and $10 \mathrm{~mol} / \mathrm{L}$ acid concentration. In these latter cases, the reactions that take place are faster and lead directly to the formation of strong geopolymer structures at room temperature. Thus, the heat supplied has rather triggered the dehydroxylation of the binding phase, leading to the formation of cracks, hence weakening of the structure. The strength of geopolymer obtained with $10 \mathrm{~mol} / \mathrm{L}$ of phosphoric acid continues to

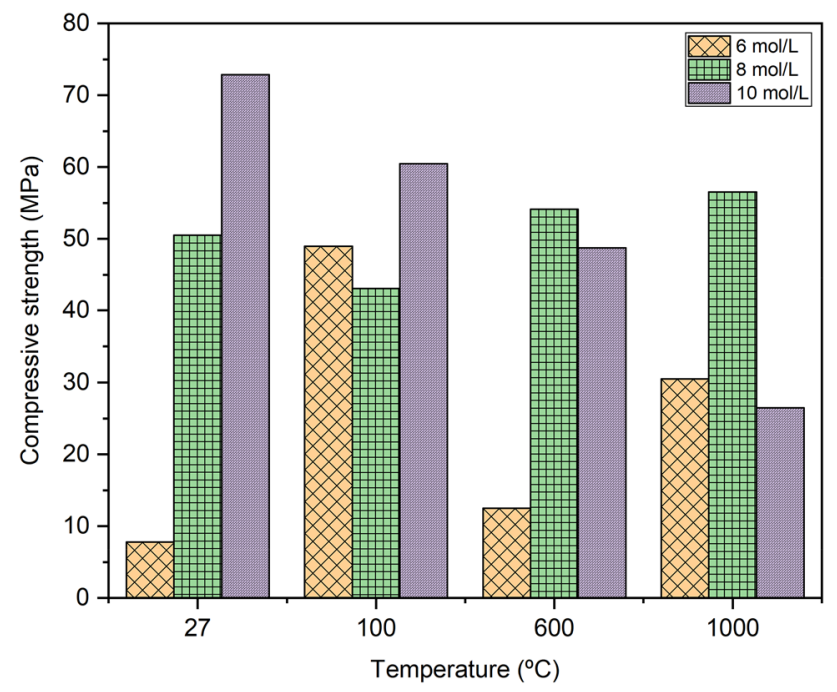

Fig. 11 Compressive strength evolution of geopolymers with temperature decrease till the temperature $1000^{\circ} \mathrm{C}(26.5 \mathrm{MPa})$, whereas the strength of geopolymer obtained with $8 \mathrm{~mol} / \mathrm{L}$ of phosphoric acid ( $56.5 \mathrm{MPa}$ ) remains high compared to the one before heating. This difference of behaviour might be due to the pores size distribution of the geopolymers. In fact, the geopolymer obtained with $8 \mathrm{~mol} / \mathrm{L}$ of phosphoric has high number of pores with various diameters, which allows easy evaporation of water during the dehydroxylation stage of the binder with less impact on compressive strength.

\subsubsection{Scanning electron microscopy-EDX}

The microstructures of unheated geopolymers are shown in Fig. 12. The micrographs are characterized by the presence of several cracks that might come from the evaporation of water during the geopolymerization. That process is fostered by the heat released during the reaction, as when volcanic ash is mixed with the phosphoric acid an exothermic reaction occurs. It was reported that in phosphate cement the temperature of the fresh paste can reach up to $100^{\circ} \mathrm{C}$ depending on the mix design [30]. The high temperature reached is due to the presence of metal oxides $\mathrm{CaO}$ and $\mathrm{MgO}$ in volcanic ash. All the samples are composed of a dense phase characteristic of the binder. Whereas the sample obtained with $6 \mathrm{~mol} / \mathrm{L}$ shows the presence of unreacted particles translating the low formation of reaction products.

\subsection{Phases and dimensional stability}

\subsubsection{Mass loss and phase stability}

The monitoring of the mass change, the phases transformation and transition of the geopolymer with temperature were carried out by TGA-DSC (Fig. 13). The TGA curves are characterized by a single mass loss of 13-14 wt $\%$ which starts nearly at room temperature and ends at around $600{ }^{\circ} \mathrm{C}$. That mass loss is accompanied by an endothermic peak at $86^{\circ} \mathrm{C}$. These changes correspond to the removal of free water contained in the pores network and the dehydroxylation of polymer chains of the geopolymer binder [31, 32]. Between 600 and $1000^{\circ} \mathrm{C}$, there is not any significant mass change. The DSC curves show respectively a succession of three small exothermic peaks at $634-657^{\circ} \mathrm{C}, 690$ and $820^{\circ} \mathrm{C}$, and an endothermic peak at $805^{\circ} \mathrm{C}$. The first one $\left(634-657^{\circ} \mathrm{C}\right)$ corresponds to the crystallization of ferrous/ferric phosphate minerals from the amorphous phase. In the crystallization process of iron phosphate glasses, that first peak is generally followed by a second exothermic peak at $820^{\circ} \mathrm{C}$ related to the crystallization of ferric phosphate minerals $\left(\mathrm{FePO}_{4}\right)[33,34]$. The latter obviously confirms the crystallization of iron 

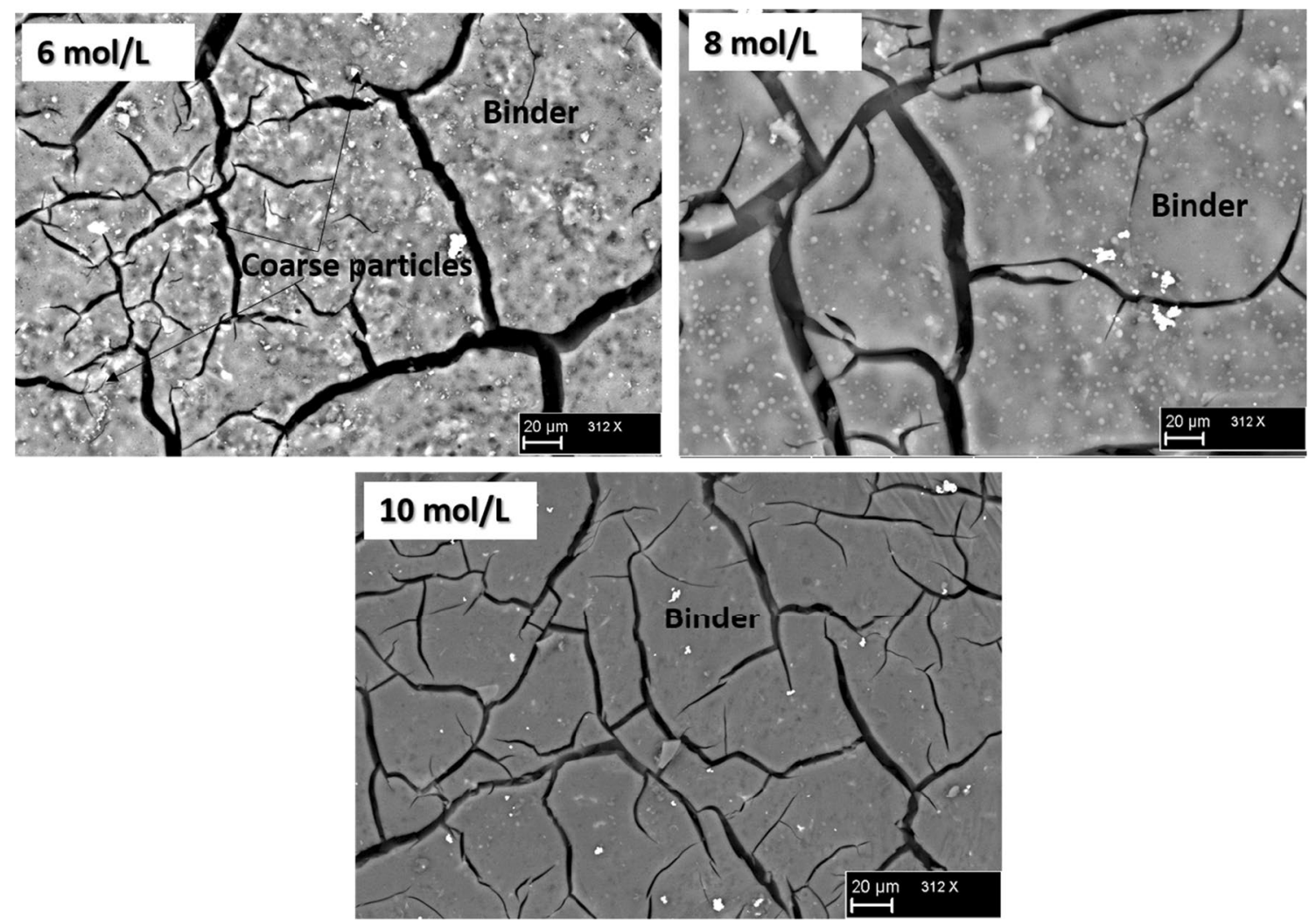

Fig. 12 Micrographs of unheated geopolymer samples

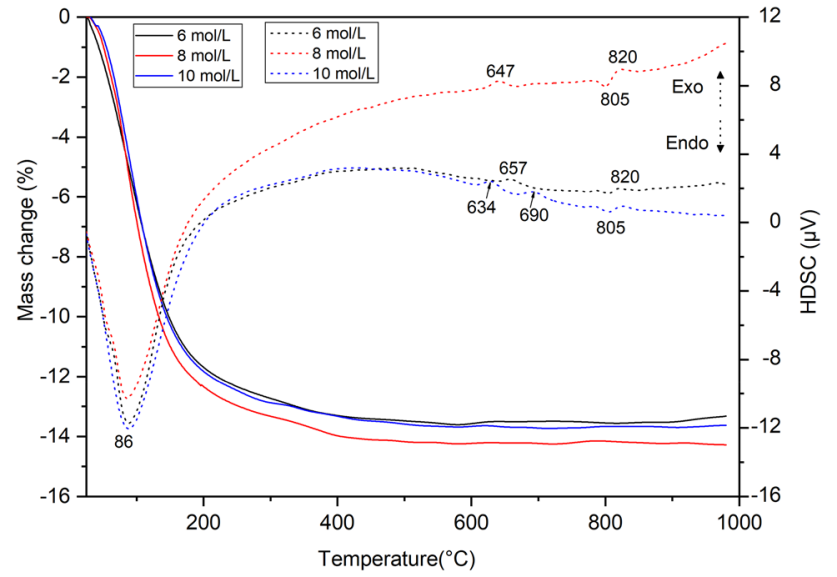

Fig. 13 TGA (solid lines) and DSC (dotted lines) curves of geopolymers with varying phosphoric acid concentrations

(III) phosphate identified only in the XRD patterns of geopolymer maintained at $1000^{\circ} \mathrm{C}$. The endothermic peak at $805^{\circ} \mathrm{C}$ corresponds to the decomposition of remaining amorphous iron phosphate $\mathrm{FePO}_{4}$ to crystallized $\mathrm{Fe}_{2} \mathrm{O}_{3}$ [33]. This confirms the crystallization of hematite observed in XRD patterns. Noteworthy that during the phase transition of iron phosphate there is sometimes a competition between decomposition $\mathrm{FePO}_{4}$ into $\mathrm{Fe}_{2} \mathrm{O}_{3}$ and the crystallization of new form of $\mathrm{FePO}_{4}$ [35]. The temperature of the apparition of the first exothermic peak $\left(634-657^{\circ} \mathrm{C}\right)$ shifts to lower value with increasing phosphoric acid concentration. This is due to the increase of the content of $\mathrm{Fe}^{2+} / \mathrm{Fe}^{3+}$ ions in the bulk composition [33]. The exothermic peak appearing at $690^{\circ} \mathrm{C}$ corresponds to the crystallization of aluminum phosphate and /or tridymite [27].

\subsubsection{Dimensional stability}

The dilatometry curves (Fig. 14a) show that up to $1000^{\circ} \mathrm{C}$, thermal linear shrinkage of geopolymers are 1.8, 2.9 and $3.1 \%$ respectively. These shrinkages are mainly observed in two temperature ranges $\left(110-140^{\circ} \mathrm{C}\right.$ and $\left.630-665 \mathrm{oC}\right)$. It is worth pointing out that beyond $1000^{\circ} \mathrm{C}$ the higher sintering of volcanic ash particles induces the beginning of melting of mineral phases $[10,11]$. This can explain the higher shrinkage beyond $1000^{\circ} \mathrm{C}$. Hence, this shrinkage was not included in the total shrinkage calculation because the material melts and does not withstand. The first shrinkage occurs between 25 to $600{ }^{\circ} \mathrm{C}$ and reaches the maximum at $110-140^{\circ} \mathrm{C}$. This shrinkage is of about $1.6,2.3$ and $2.4 \%$ for geopolymer specimens obtained respectively with 6 , 8 and $10 \mathrm{~mol} / \mathrm{L}$ of phosphoric acid. The increase of the first 

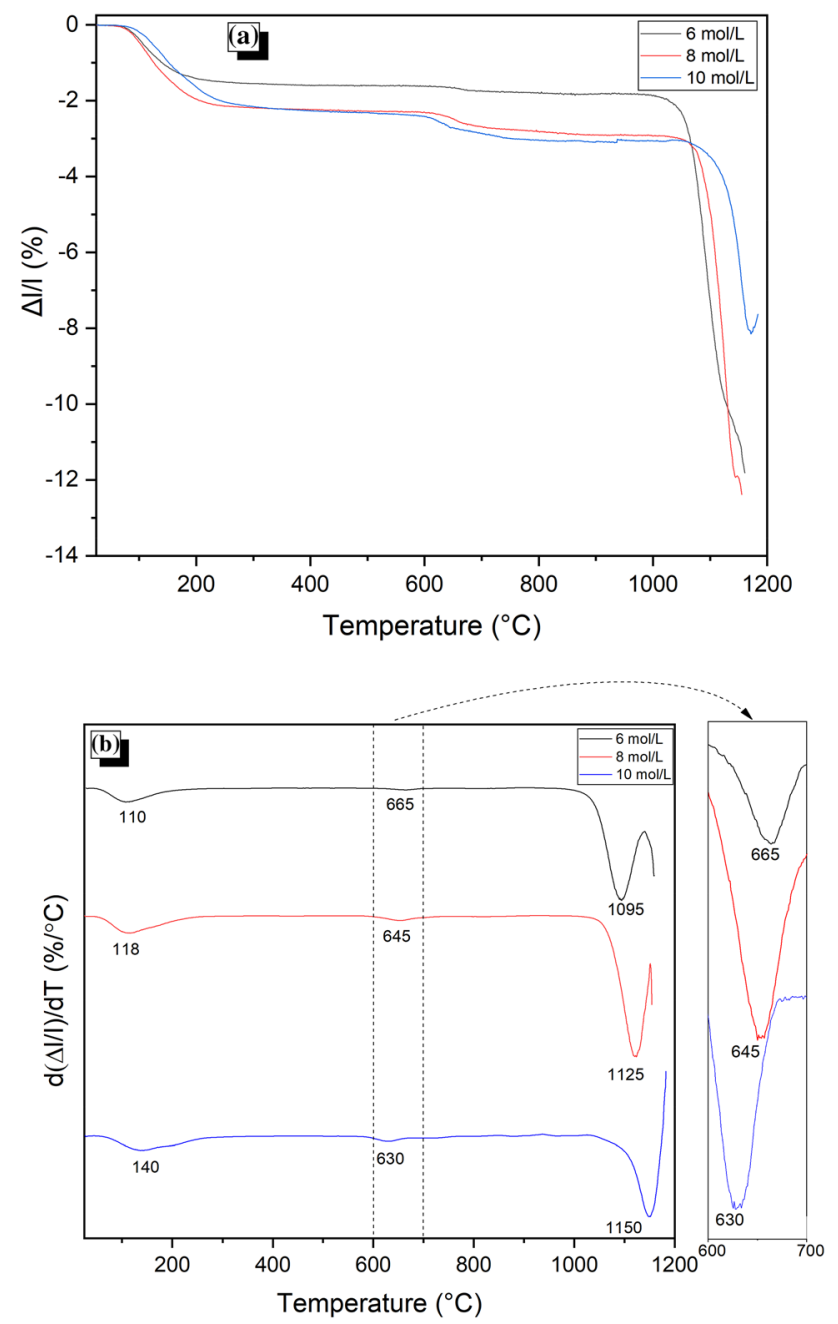

Fig. 14 Dimension change with temperature (a) \% of expansion; (b) differential of the $\%$ of the expansion

shrinkage with phosphoric acid concentration correlates with the extent of cracks as observed on the surface of specimens after exposure at $100^{\circ} \mathrm{C}$ (Fig. 8). This shrinkage is linked to the mass loss recorded in TGA and which corresponds to the evaporation of water. The second shrinkage begins at around $600{ }^{\circ} \mathrm{C}$ and ends before $1000{ }^{\circ} \mathrm{C}$, and is about $0.2,0.6$ and $0.7 \%$ for geopolymer specimens obtained respectively with 6,8 and $10 \mathrm{~mol} / \mathrm{L}$ of phosphoric acid. This second shrinkage, which does not correspond to any mass loss, is due to the crystallization of ferrous/ ferric phosphate minerals. The shift of the maximum temperature related to this second shrinkage (Fig. 14b) agrees with the similar phenomenon observed in the DSC curves (Fig. 13), and which was ascribed to the increase of the amount of $\mathrm{Fe}^{2+} / \mathrm{Fe}^{3+}$ ions in the bulk composition. The latter arising from the increased dissolution of the reactive phase of volcanic ash with the increase of phosphoric acid concentration. Most interesting in the differential curve of the percentage of expansion beyond $1000^{\circ} \mathrm{C}$ is the delay of the temperature at which maximum shrinkage due to melting occurs (Fig. 14b). Such behaviour means that the increase of the dosage of phosphate bonds in the geopolymer binder prevents the early melting of phases.

\section{Conclusion}

The influence of phosphoric acid concentration on the thermal stability of volcanic ash-based phosphate geopolymers was reported. It appears that changes occurring in mineralogical phases are highly sensitive to temperature and phosphoric acid concentration. The major phases including geopolymer binder remain stable up to $1000^{\circ} \mathrm{C}$ and beyond the latter temperature, the melting of geopolymers becomes predominant. The geopolymer binder is based on ferro-silico-aluminophosphate $\left(\mathrm{AlPO}_{4}-\mathrm{SiO}_{2}-\mathrm{FePO}_{4}\right)$ chains. The total porosity of unheated geopolymers decreases from 22 to $10 \%$ with increasing phosphoric acid concentration. The heterogeneity of pore diameter distribution enhances the thermal stability of geopolymers in terms of strength loss and thermal shrinkage. The maximum strength loss was $63 \%$ and the highest thermal shrinkage $3 \%$ after heating geopolymers up to $1000^{\circ} \mathrm{C}$. The geopolymers produced with a phosphoric acid concentration of $8 \mathrm{~mol} / \mathrm{L}$ demonstrated superior thermal stability. Thus, phosphate geopolymer is suitable for high-temperature applications up to $1000^{\circ} \mathrm{C}$.

Acknowledgements Open Access funding provided by Projekt DEAL. This work was supported by the Alexander von Humboldt Foundation through the Georg Foster Postdoctoral research fellowship (CMR-1201499-GF-P). The authors are also grateful to Dr Elie Kamseu and Mr. Sylvain Tome for assistance in materials characterisation.

\section{Compliance with ethical standards}

Conflict of interest On behalf of all authors, the corresponding author states that there is no conflict of interest.

Open Access This article is licensed under a Creative Commons Attribution 4.0 International License, which permits use, sharing, adaptation, distribution and reproduction in any medium or format, as long as you give appropriate credit to the original author(s) and the source, provide a link to the Creative Commons licence, and indicate if changes were made. The images or other third party material in this article are included in the article's Creative Commons licence, unless indicated otherwise in a credit line to the material. If material is not included in the article's Creative Commons licence and your intended use is not permitted by statutory regulation or exceeds the permitted use, you will need to obtain permission directly from the copyright holder. To view a copy of this licence, visit http://creativecommons .org/licenses/by/4.0/. 


\section{References}

1. Davidovits J (2015) Geopolymer chemistry and applications, 4th edn., Institut Géopolymère, Saint-Quentin

2. Ke X, Bernal SA, Ye N, Provis JL, Yang J (2015) One-part geopolymers based on thermally treated red mud/ $\mathrm{NaOH}$ blends. J Am Ceram Soc 98:5-11. https://doi.org/10.1111/jace.13231

3. Ouellet-Plamondon C, Habert G (2015) Life cycle assessment (LCA) and innovative applications of alkali-activated cements and concretes. In: Handbook of alkali-activated cements, mortars and concretes 2015, pp 663-686

4. Davidovits J (2015) False values on CO2 emission for geopolymer cement/concrete published. Sci Pap Geopolymer Inst Libr TechPap 24:1-9

5. Rivera OG, Long WR, Weiss CA, Moser RD, Williams BA, TorresCancel K, Gore ER, Allison PG (2016) Effect of elevated temperature on alkali-activated geopolymeric binders compared to portland cement-based binders. Cem Concr Res 90:43-51. https://doi.org/10.1016/j.cemconres.2016.09.013

6. Yadollahi MM, Benli A, Demirboğa R (2015) Effects of elevated temperature on pumice based geopolymer composites. Plast Rubber Compos 44:226-237. https://doi.org/10.1179/17432 89815 Y.0000000020

7. Tchakouté HK, Rüscher CH, Kong S, Kamseu E, Leonelli C (2016) Thermal behavior of metakaolin-based geopolymer cements using sodium waterglass from rice husk ash and waste glass as alternative activators. Waste Biomass Valoriz. https://doi. org/10.1007/s12649-016-9653-7

8. Elimbi A, Tchakoute HK, Kondoh M, Manga JD, Dika Manga J (2014) Thermal behavior and characteristics of fired geopolymers produced from local Cameroonian metakaolin. Ceram Int 40:4515-4520. https://doi.org/10.1016/j.ceramint.2013.08.126

9. Bernal SA, Rodríguez ED, Mejía De Gutiérrez R, Gordillo M, Provis JL (2011) Mechanical and thermal characterisation of geopolymers based on silicate-activated metakaolin/slag blends. J Mater Sci 46:5477-5486. https://doi.org/10.1007/s1085 3-011-5490-z

10. Lemougna PN, MacKenzie KJD, Melo UFC (2011) Synthesis and thermal properties of inorganic polymers (geopolymers) for structural and refractory applications from volcanic ash. Ceram Int 37:3011-3018. https://doi.org/10.1016/j.ceram int.2011.05.002

11. Lemougna PN, Chinje Melo UF, Delplancke MP, Rahier H (2013) Influence of the activating solution composition on the stability and thermo-mechanical properties of inorganic polymers (geopolymers) from volcanic ash. Constr Build Mater 48:278-286. https://doi.org/10.1016/j.conbuildmat.2013.06.089

12. Kong DLY, Sanjayan JG, Sagoe-Crentsil K (2007) Comparative performance of geopolymers made with metakaolin and fly ash after exposure to elevated temperatures. Cem Concr Res 37:1583-1589. https://doi.org/10.1016/j.cemconres.2007.08.021

13. Kong DLY, Sanjayan JG (2010) Effect of elevated temperatures on geopolymer paste, mortar and concrete. Cem Concr Res 40:334-339. https://doi.org/10.1016/j.cemconres.2009.10.017

14. Le-ping L, Xue-min C, Shu-heng Q, Jun-li Y, Lin Z (2010) Preparation of phosphoric acid-based porous geopolymers. Appl Clay Sci 50:600-603. https://doi.org/10.1016/j.clay.2010.10.004

15. Le-ping L, Xue-min C, Yan H, Si-dong L, Si-yu G (2012) The phase evolution of phosphoric acid-based geopolymers at elevated temperatures. Mater Lett 66:10-12. https://doi.org/10.1016/j. matlet.2011.08.043

16. Khabbouchi M, Hosni K, Mezni M, Zanelli C, Doggy M, Dondi M, Srasra E (2017) Interaction of metakaolin-phosphoric acid and their structural evolution at high temperature. Appl Clay Sci 146:510-516. https://doi.org/10.1016/j.clay.2017.07.006

17. Nobouassia Bewa C, Tchakouté HK, Fotio D, Rüscher $\mathrm{CH}$, Kamseu $\mathrm{E}$, Leonelli C (2018) Water resistance and thermal behavior of metakaolin-phosphate-based geopolymer cements. J Asian Ceram Soc 6:271-283. https://doi.org/10.1080/21870 764.2018.1507660

18. Celerier H, Jouin J, Tessier-Doyen N, Rossignol S (2018) Influence of various metakaolin raw materials on the water and fire resistance of geopolymers prepared in phosphoric acid. J Non Cryst Solids 500:493-501. https://doi.org/10.1016/j.jnoncrysol .2018.09.005

19. Djobo JNY, Tchadjié LN, Tchakoute HK, Kenne BBD, Elimbi A, Njopwouo D (2014) Synthesis of geopolymer composites from a mixture of volcanic scoria and metakaolin. J Asian Ceram Soc 2:387-398. https://doi.org/10.1016/j.jascer.2014.08.003

20. Lemougna PN, Chinje Melo UF, Delplancke MP, Rahier H (2014) Influence of the chemical and mineralogical composition on the reactivity of volcanic ashes during alkali activation. Ceram Int 40:811-820. https://doi.org/10.1016/j.ceramint.2013.06.072

21. Djobo JNY, Elimbi A, Tchakouté HK, Kumar S (2016) Reactivity of volcanic ash in alkaline medium, microstructural and strength characteristics of resulting geopolymers under different synthesis conditions. J Mater Sci 51:10301-10317. https://doi. org/10.1007/s10853-016-0257-1

22. Chen Y, Brantley SL (1997) Temperature- and pH-dependence of albite dissolution rate at acid pH. Chem Geol 135:275-290. https ://doi.org/10.1016/S0009-2541(96)00126-X

23. McAdam AC, Zolotov MY, Sharp TG, Leshin LA (2008) Preferential low-pH dissolution of pyroxene in plagioclase-pyroxene mixtures: implications for martian surface materials. Icarus 196:90-96. https://doi.org/10.1016/j.icarus.2008.01.008

24. Reale P, Scrosati B, Delacourt C, Wurm C, Morcrette M, Masquelier $C$ (2003) Synthesis and thermal behavior of crystalline hydrated iron(III) phosphates of interest as positive electrodes in li batteries. Chem Mater 15:5051-5058. https://doi.org/10.1021/cm031 $107 z$

25. Khan MI, Min TK, Azizli K, Sufian S, Ullah H, Man Z (2015) Effective removal of methylene blue from water using phosphoric acid based geopolymers: synthesis, characterizations and adsorption studies. RSC Adv. 5:61410-61420. https://doi.org/10.1039/c5ra0 $8255 b$

26. Guo CM, Wang KT, Liu MY, Li XH, Cui XM (2016) Preparation and characterization of acid-based geopolymer using metakaolin and disused polishing liquid. Ceram Int 42:9287-9291. https:// doi.org/10.1016/j.ceramint.2016.02.073

27. Lassinantti Gualtieri M, Romagnoli M, Gualtieri AF (2015) Preparation of phosphoric acid-based geopolymer foams using limestone as pore forming agent-thermal properties by in situ XRPD and Rietveld refinements. J Eur Ceram Soc 35(2015):31673178. https://doi.org/10.1016/j.jeurceramsoc.2015.04.030

28. Djobo JNY, Elimbi A, Tchakouté HK, Kumar S (2016) Mechanical activation of volcanic ash for geopolymer synthesis: effect on reaction kinetics, gel characteristics, physical and mechanical properties. RSC Adv 6:39106-39117. https://doi.org/10.1039/ c6ra03667h

29. Basile-Doelsch I, Amundson R, Stone WEE, Masiello CA, Bottero JY, Colin F, Masin F, Borschneck D, Meunier JD (2005) Mineralogical control of organic carbon dynamics in a volcanic ash soil on La Réunion. Eur J Soil Sci 56:689-703. https://doi.org/10.111 1/j.1365-2389.2005.00703.x

30. Liu Y, Qin Z, Chen B (2020) Influence of low-grade bauxite on the properties of magnesium phosphate cement. Constr Build Mater 242:118052. https://doi.org/10.1016/j.conbuildma t.2020.118052 
31. Lassinantti Gualtieri M, Romagnoli M, Pollastri S, Gualtieri AF (2015) Inorganic polymers from laterite using activation with phosphoric acid and alkaline sodium silicate solution: mechanical and microstructural properties. Cem Concr Res 67:259-270. https://doi.org/10.1016/j.cemconres.2014.08.010

32. Wang YS, Provis JL, Dai JG (2018) Role of soluble aluminum species in the activating solution for synthesis of silico-aluminophosphate geopolymers. Cem Concr Compos 93:186-195. https://doi.org/10.1016/j.cemconcomp.2018.07.011

33. Ray CS, Fang X, Karabulut M, Marasinghe GK, Day DE (1999) Effect of melting temperature and time on iron valence and crystallization of iron phosphate glasses. J Non Cryst Solids 249:1-16. https://doi.org/10.1016/S0022-3093(99)00304-X
34. Oliver CJRG, Lovey FC, Caneiro A, Russo DO, Rodríguez DS, Soldera F, Fiscina JE, Rincón JM (2010) Crystallization of iron phosphate glasses containing up to $19 \mathrm{wt} . \%$ UO2.67. J Non Cryst Solids 356:2986-2993. https://doi.org/10.1016/j.jnoncrysol .2010.06.034

35. Aliouane N, Badeche T, Gagou Y, Nigrelli E, Saint-Gregoire $P$ (2000) Synthesis and phase transitions of iron phosphate. Ferroelectrics 241:255-262. https://doi.org/10.1080/0015019000 8224999

Publisher's Note Springer Nature remains neutral with regard to jurisdictional claims in published maps and institutional affiliations. 